\title{
Chemotherapy for Hepatocellular Carcinoma: Current Evidence and Future Perspectives
}

\author{
Emanuele Rinninella*1,2 ${ }^{1}$, Lucia Cerrito ${ }^{1}$, Irene Spinelli ${ }^{1}$, Marco Cintoni $^{2}$, Maria Cristina Mele ${ }^{2}$, \\ Maurizio Pompili ${ }^{1}$ and Antonio Gasbarrini ${ }^{1}$ Catholic University of Sacred Heart, Rome, Italy; ${ }^{2}$ Clinical Nutrition Unit, Gastroenterology Area, Fondazione Policlinico Universitario Agostino Gemelli, Catholic University of Sacred Heart, Rome, Italy \\ ${ }^{1}$ Internal Medicine and Gastroenterology Unit, Gastroenterology Area, Fondazione Policlinico Universitario Agostino Gemelli,
}

\begin{abstract}
Hepatocarcinogenesis is a multistep process, heralded by abnormalities in cell differentiation and proliferation and sustained by an aberrant neoangiogenesis. Understanding the underlying molecular pathogenesis leading to hepatocellular carcinoma is a prerequisite to develop new drugs that will hamper or block the steps of these pathways. As hepatocellular carcinoma has higher arterial vascularization than normal liver, this could be a good target for novel molecular therapies. Introduction of the antiangiogenic drug sorafenib into clinical practice since 2008 has led to new perspectives in the management of this tumor. The importance of this drug lies not only in the modest gain of patients' survival, but in having opened a roadmap towards the development of new molecules and targets. Unfortunately, after the introduction of sorafenib, during the last years, a wide number of clinical trials on antiangiogenic therapies failed in achieving significant results. However, many of these trials are still ongoing and promise to improve overall survival and progression-free survival. A recent clinical trial has
\end{abstract}

Keywords: Hepatocellular carcinoma; Molecular target therapies; Immunotherapy; Branched-chain amino acids.

Abbreviations: $\alpha \mathrm{FP}, \alpha$-Fetoprotein; $\mathrm{AE}$, adverse event; Ang-2, angiopoietin- 2 ; APCs, antigen presenting cells; BCAAs, branched-chain amino acids; BCLC, Barcelona Clinic Liver Cancer; c-Kit, tyrosine-protein kinase Kit; C-MET, tyrosine protein kinase Met; CI, confidence interval; CTLA-4, cytotoxic T lymphocyte antigen-4; DCR, disease control rate; ECOG, Eastern Cooperative Oncology Group; EGF, epidermal growth factor; ERK, extracellular signal-regulated kinase; FDA, Food and Drug Administration; FGF, fibroblast growth factor; FGFR, fibroblast growth factor receptor; FLT-3, Fms-like tyrosine inase-3; HBV, hepatitis B virus; HCC, hepatocellular carcinoma; HCV, hepatitis C virus; HFSR, hand-foot skin reaction; HGF, hepatocyte growth factor; HR, hazard ratio; Ig, immunoglobulin; MAPK, mitogen-activated protein kinases; MEK, mitogen-activated protein extracellular kinase; mRECIST, modified Response Evaluation Criteria in Solid Tumors; mTOR, mammalian target of rapamycin; MWA, microwave ablation ORR, overall response rate; OS, overall survival; PD-1, programmed cell death protein-1; PDGF, platelet-derived growth factor; PDGFR, platelet-derived growth factor receptor; PDL, programmed cell death protein; PEI, percutaneous alcoho injection; PFS, progression-free survival; PI3K, phosphoinositol 3-kinase; PR, partial response; PS, performance status; PTEN, tumor suppressor phosphatase and tensin homolog; RECIST, Response Evaluation Criteria in Solid Tumors; RET, rearranged during transfection; RFA, radiofrequency ablation; SCGFR, stem cell growth factor receptor; SD, stable disease; TACE, transarterial chemoembolization; TARE, transarterial radioembolization; TIE2, tyrosine kinase with immunoglobulin-like and EGF-like domains 1 ; Tregs, T regulatory cells; TTP, time to progression; VEGF, vascular endothelial growth factor; VEGFR, vascular endothelial growth factor receptor.

Received: 9 January 2017; Revised: 29 April 2017; Accepted: 29 April 2017

*Correspondence to: Emanuele Rinninella, Gastroenterology Area, Fondazione Policlinico Universitario Agostino Gemelli, Catholic University of Sacred Heart, Rome 00168, Italy. Tel: +39-06-3015-6265, E-mail: e.rinninella@gmail.com proven regorafenib effective in patients showing tumor progression under sorafenib, thus opening new interesting therapeutic perspectives. Many other expectations have been borne from the discovery of the immune checkpoint blockade, already known in other solid malignancies. Furthermore, a potential role in hepatocellular carcinoma therapy may derive from the use of branched-chain amino acids and of nutritional support. This review analyses the biomolecular pathways of hepatocellular carcinoma and the ongoing studies, the actual evidence and the future perspectives concerning drug therapy in this open field.

Citation of this article: Rinninella $E$, Cerrito $L$, Spinelli I, Cintoni M, Mele MC, Pompili $M$, et al. Chemotherapy for hepatocellular carcinoma: current evidence and future perspectives. J Clin Transl Hepatol 2017;5(3):235-248. doi: 10.14218/JCTH.2017.00002.

\section{Introduction}

\section{Epidemiology}

Hepatocellular carcinoma (HCC) is the sixth most frequent neoplasia ( 749,000 new cases/year), with a constantly increasing worldwide incidence and about 745,000 deaths/year. ${ }^{1}$ It represents the third cause of tumor-related death $(692,000$ cases/year), and its incidence is higher in males (M/F ratio of 2.4), mainly affecting people in the sixth to seventh decade of life. 2,3 The incidence of HCC is higher in Chinese and blackAfrican populations, representing $85 \%$ of all HCC diagnoses worldwide; moreover, younger patients are usually involved, especially for the hepatitis B virus (HBV)-related cirrhosis. Hepatitis $C$ virus (HCV)-related liver disease, on the other hand, is the main cause of chronic liver disease leading to HCC in Europe, the United States and Japan. ${ }^{2}$ In general, in developed countries (Europe, the United States and Japan) the incidence is low, with the exception of Southern Europe. ${ }^{4}$

\section{Risk factors}

In $90 \%$ of cases, HCC is associated with a well-identified risk factor, the most important of which are HBV and HCV chronic hepatitis, alcohol intake and exposure to toxic agents (e.g. aflatoxin $\mathrm{B}$ ). HBV infection is predominant in Eastern Asia and Africa (60\%), while HCV is predominant in Europe, Japan and Northern America (50-60\%). According to global incidence, 
Rinninella E. et al: Chemotherapy for HCC

$54 \%$ cases of $\mathrm{HCC}$ are due to HBV infection and $31 \%$ to $\mathrm{HCV}^{5,6}$

HBV is a risk factor for HCC in both cirrhotic livers (annual incidence of 2-6\%) and non-cirrhotic ones (annual incidence of $0.5 \%) .{ }^{7}$ In the latter case, HBV directly acts as a carcinogenic factor through its integration in the hepatocyte genome, determining genomic instability. ${ }^{8,9}$ Exposure to aflatoxin enhances the possibility of generating $\mathrm{HCC}$, especially in the case of concurrent HBV infection; ${ }^{10}$ this is frequent in developing nations, where food conservation is altered by poor lifestyle and climatic conditions. ${ }^{11}$

In the majority of cases, HCC emerges in cirrhotic livers, with an estimated risk of 3-4\% patients per year, regardless of etiology; ${ }^{12}$ chronic viral infection (HBV, HCV) and alcoholic liver disease are the most well known risk factors. Autoimmune hepatitis, primary biliary cholangitis, inherited metabolic diseases (hemochromatosis, alpha-1-antitrypsin deficiency, and Wilson's disease) are other less frequent risk factors. ${ }^{13-15}$ Obesity, non-alcoholic fatty liver disease and diabetes mellitus have been recently associated with advanced liver fibrosis. ${ }^{16}$ Current evidence indicates that these factors, and in particular insulin-resistance, are also clearly associated with HCC. ${ }^{17-19}$ On the other hand, observational studies have shown that the use of metformin and statins could prevent the risk of $\mathrm{HCC}_{1}{ }^{20}$ but randomized clinical trials are unavailable on this topic.

\section{Standard-of-care}

The therapeutic strategy for HCC is defined by the Barcelona Clinic Liver Cancer (BCLC) classification, which considers the three important variables of tumor staging (size, number of nodules, vascular invasion and/or extrahepatic disease), liver function evaluation (using the Child-Pugh score) and performance status (PS), according to the Eastern Cooperative Oncology Group (ECOG). ${ }^{21}$

In the early stages and according to tumor location and number, liver function and portal hypertension assessment, surgical resection and percutaneous ablation (including radiofrequency ablation (RFA), microwave ablation (MWA) and percutaneous alcohol injection (PEI)) are the main therapeutic strategies. Liver transplantation may be taken into account in patients younger than 70 years old without significant comorbidities and with HCC staged within Milan or slightly enlarged criteria (up to seven, according to the University of California, San Francisco), independent from the degree of liver function failure or portal hypertension. ${ }^{22-24}$

Trans-arterial chemoembolization (TACE) should be offered to patients with intermediate BCLC tumor stage (preserved function, PS $=0$, large or multifocal tumors, no vascular invasion or extra-hepatic spread). ${ }^{21,25,26}$ Advanced HCC in compensated patients are treated with sorafenib. To date, it represents the only systemic therapy with a documented improvement in overall survival (OS). ${ }^{27}$ Even if there are not yet results from prospective randomized clinical trials, Yttrium 90 trans-arterial radio embolization (TARE) is an effective tool, often used in large specialized centers for the treatment of intermediateadvanced HCC with unfavorable predictors of response or non-responders to TACE, such as patients with macroscopic vascular invasion. ${ }^{28,29}$ In some circumstances, it has been used as a bridge to liver transplantation. ${ }^{30}$

Curative strategies (resection, PEI, RFA, liver transplantation) are limited to the early stage, cases of which account for less than $40 \%$ of the neo-diagnoses of HCC. Palliative treatments (TACE, sorafenib and TARE) are effective but they can only prolong survival. ${ }^{21}$

\section{Advanced HCC: the field of molecular target therapies}

Molecule-targeted therapies represent a new promising field in advanced HCC treatment. They are based on the identification of different carcinogenetic mechanisms.

\section{Classical molecular targets in HCC}

Molecular mechanisms involved in the pathogenesis of HCC are represented by altered intracellular signal transmission as well as angiogenetic and growth factors. Accordingly, specific targets were established for the treatment of HCC. Currently established treatments are represented by tyrosine kinase inhibitors and monoclonal antibodies.

The most evaluated molecular intracellular pathways, to date, are the following (Fig. 1):

- Ras/Raf/MEK/ERK (MAPK) pathway, characterized by the phosphorylation of four major kinases: Ras, Raf, mitogen-activated protein extracellular kinase (MEK), and extracellular signal-regulated kinase (ERK). This pathway is the most frequently hyper-activated in HCC (about $50 \%$ of early stage cases and the majority of advanced ones). ${ }^{31}$

- Wnt/catenin pathway, characterized by the Wnt protein binding to its ligand, which results in the accumulation and activation of $\beta$-catenin in cells that in turn is rapidly transferred to the nucleus, where it regulates transcriptional mechanisms. Around $50 \%$ of all patients with HCCs have activation of the WNT signaling pathway. ${ }^{32,33}$

- Phosphoinositol 3-kinase (PI3K)/Akt/mammalian target of rapamycin (mTOR) pathway, activated in $30-50 \%$ of HCCs. ${ }^{34}$ It is localized downstream of several receptor tyrosine kinases (e.g. ERK), controlling cellular replication, apoptosis and cell motility, and involved in invasiveness and metastasis. ${ }^{35,36}$ PI3K is partially controlled by the tumor suppressor phosphatase and tensin homolog (PTEN) protein, that is frequently mutated in $\mathrm{HCC}^{37}$ The overstimulation of this pathway leads to the inactivation of some apoptotic mechanisms, determining the hyperactivation of mTOR, an enzyme serving a pivotal role in cellular proliferation and angiogenesis. ${ }^{38}$

Several growth factors (and their receptors) involved in hepatic carcinogenesis have been identified. HCC is a highly vascularized tumor and both vascular endothelial growth factor (VEGF) and angiopoietin-2 (Ang-2) are key elements for tumor emergence and proliferation; in particular, VEGF promotes the growth, migration and morphogenesis of endothelial cells, and increases vascular permeability. ${ }^{39,40} \mathrm{~A}$ vascular targeting approach is crucial in HCC treatment; several studies have demonstrated that high-density vascularization is a predictor of poor response to treatment and shorter disease-free period after hepatic resection. ${ }^{41,42}$ Platelet derived growth factor (PDGF) determines the involvement of pericytes and smooth muscle cells around the new vascular shoots. ${ }^{43}$ These factors are strictly related to metastatic potential of tumor cells; for this reason, their inhibitors are a promising therapeutic agent. ${ }^{44}$

Epidermal growth factor (EGF) is frequently overexpressed in $\mathrm{HCC}_{i}{ }^{45,46}$ other involved factors are fibroblast growth factor (FGF), whose signal are involved in Ras/Raf/MAPK 
Rinninella E. et al: Chemotherapy for HCC

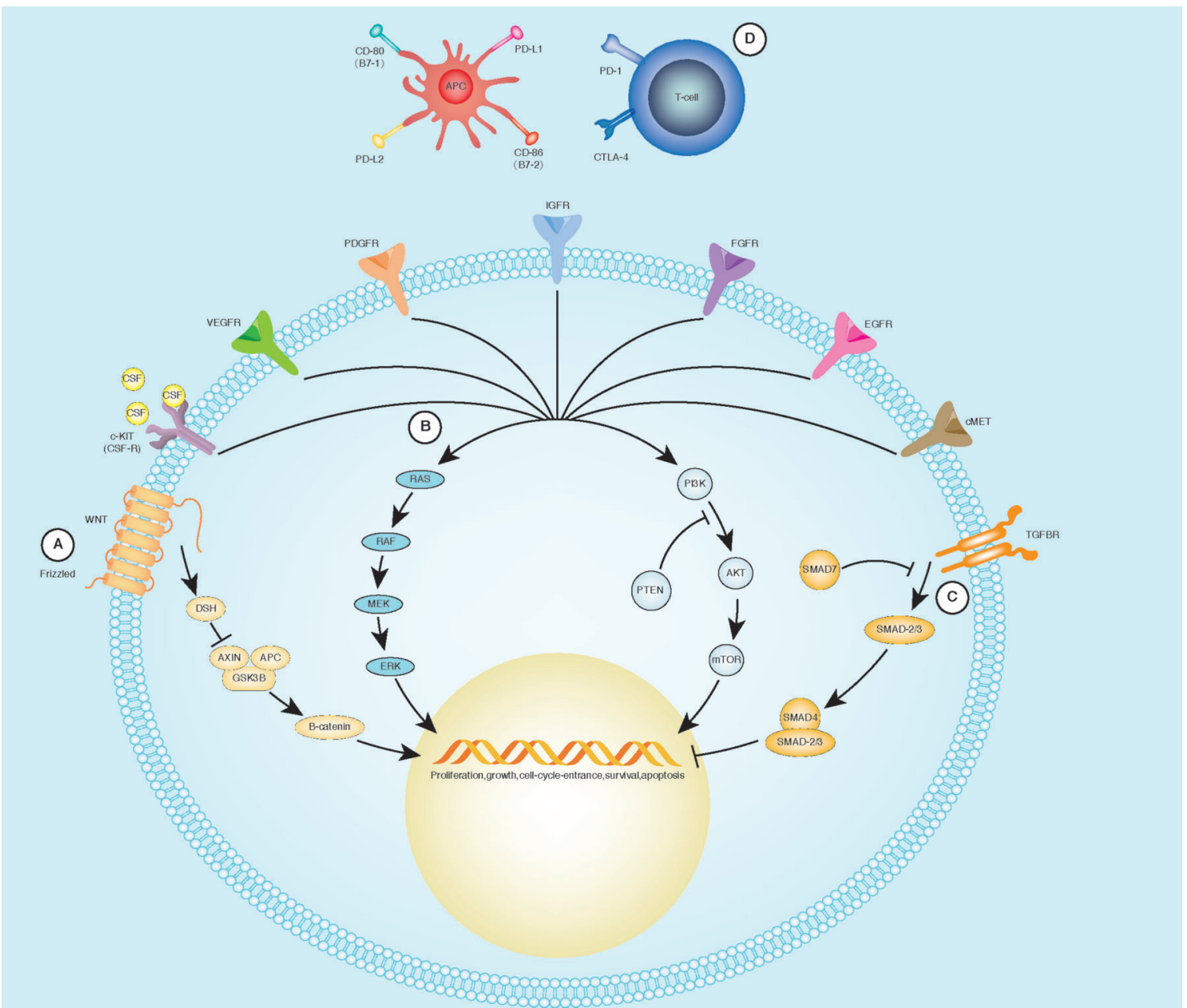

Fig. 1. Main molecular pathways in HCC pathogenesis. (A) The activation of Frizzled (WNT receptor) determines the recruitment of disheveled (DSH), preventing the destruction of $\beta$-catenin through the dissolution of a molecular complex composed by Axin, adenomatosis polyposis coli (APC), and glycogen synthase kinase 3 $\beta$ (GDK3B). (B) Growth factors bind their specific receptors, leading to their dimerization and activation of the tyrosine-kinase. From this point, it is possible to recruit two different groups of molecules: MAPK and PI3K pathways, culminating with modifications in cell-cycle regulation, protein synthesis, and gene transcription. (C) Stimulation of TGF- $\beta$ R recruits the SMAD complex, leading to a negative regulation of the cellular cycle. (D) CTLA-4 and its ligands: CD-80/CD-86 transmit an inhibitory signal in the antigen presenting cells (APCs), while CD-28 represents an activating signal. Programmed cell death protein-1 (PD-1), through its binding to PD-L1 (B7-1) and PD-L2 (B7-2), down-regulates the immune system and promotes self-tolerance. Adapted from Harding et al. ${ }^{121}$

pathway and tyrosine protein kinase Met (c-MET), the tyrosine kinase receptor for hepatocyte growth factor (HGF). ${ }^{47}$ The HGF-cMET axis has been implicated in tumor cell migration, invasion, proliferation, and angiogenesis. High c-Met and HGF expression correlates with early recurrence of HCC after hepatectomy and shorter survival in $\mathrm{HCC}{ }^{48}$

All these agents can become a target for HCC treatment, alone or combined with each other or to other strategies (loco-regional treatment or resection), as previous and recent trials have demonstrated.

\section{Role of sorafenib}

Traditional chemotherapy agents and hormonal therapies have been tested for HCC, but they did not improve the prognosis of these patients. An important frontier was reached with the introduction of sorafenib, a multikinase inhibitor, in the treatment of advanced HCC. This drug opened the era of molecular targeted therapy for HCC and represents the current first-line pharmacological treatment for advanced HCC.

Sorafenib is a tyrosine kinase inhibitor, targeting Raf serine/threonine kinases, vascular endothelial growth factor receptors 1-3 (VEGFR1-3), platelet-derived growth factor receptor (PDGFR)-b, tyrosine-protein kinase Kit (c-Kit), fmslike tyrosine inase-3 (FLT-3) and p38 tyrosine kinases. ${ }^{49}$ Its use in advanced HCC was approved in 2008, on the basis of the positive results of two multicenter, phase 3 studies (the so-called SHARP and Asia-Pacific trials). 27,50

SHARP was a phase 3 randomized placebo-controlled study involving 602 patients with advanced HCC (299 receiving sorafenib and 303 receiving placebo). An improvement in OS was demonstrated in the sorafenib arm: 10.7 versus 7.9 months (hazard ratio [HR] in the sorafenib group, 0.69 ; $95 \%$ confidence interval [CI]: 0.55 to $0.87 ; p<0.001) .{ }^{27}$ A similar result was obtained by the Asia-Pacific trial ( 6.5 versus 4.2 months for sorafenib and placebo respectively, $\mathrm{HR}$ 0.68 [95\% CI: $0.50-0.93] ; p=0.014)$. Sorafenib-related 
major adverse effects are diarrhea, hand-foot skin reaction (HFSR), fatigue and weight loss. In the SHARP trial, the overall incidence of treatment-related adverse events (AEs) was $80 \%$, of which most were described as grade 1 or 2 in severity. Some grade $3 \mathrm{AEs}$, such as diarrhea ( $8 \%$ vs $2 \%$ in the placebo group, $p<0.001)$ and HSFR $(8 \%$ vs $<1 \%, p<$ 0.001 ), occurred more frequently in the sorafenib group. The trial was prematurely stopped at second interim analysis for a significant survival benefit in the sorafenib arm.

For better understanding of efficacy and safety in real practice, a prospective multicenter observational study was conducted in six Italian referral hospitals. ${ }^{51}$ That study enrolled 296 patients affected by HCC in BCLC C stage $(222,75 \%)$ or BCLC B stage $(74,25 \%)$, who were unfit for or failed to respond to loco-regional treatments. Median OS was 10.5 months in the overall cohort, with results showing 8.4 months in the BCLC C patients versus 20.6 months in the BCLC B patients $(p<0.0001)$. The overall incidence of treatment-related AEs was higher than in the SHARP study $(91 \%)$, with a greater percentage of grade 3 and 4 AEs, such as fatigue (25\%) and arterial hypertension (7\%). Discontinuation, dose reduction and interruption were greater than in the SHARP study. Surprisingly, a dose reduction for AEs was associated with a better OS: 21.6 months in the patients receiving a half-dose of sorafenib (95\% CI: 13.6-29.6) compared to 9.6 months (95\% CI: 6.9-12.3) for the remaining patients, who remained at full dose.

The multivariate analysis confirmed that "full dose" treatment was an independent predictor of mortality (HR: 1.8, $95 \% \mathrm{CI}: 1.4-2.4)$. Dose reduction for AEs is common in reallife practice and may improve the treatment tolerability, following adjusting of the drug dosage to the patient; ${ }^{52}$ however, in a propensity score matching study, no differences in terms of OS and progression-free survival (PFS) have been reported between initial "half-dose" and "standard-dose" treatments. ${ }^{53}$ Indeed, a better outcome may be more related to an increased incidence of AEs leading to dose reduction, than to the dose itself. This result is better understood in the light of other observational studies showing that early AEs (such as diarrhea or HFSR) are positive predictive factors for clinical response to sorafenib therapy. ${ }^{54,55}$

Given the hypothesis that loco-regional treatments may increase the production of angiogenic factors, particularly VEGF and thus enhancing angiogenesis and metastasis, ${ }^{56}$ sorafenib was then evaluated as adjuvant therapy in combination with curative (resection, ablation) or loco-regional palliative treatments (such as TACE). The STORM trial phase 3 study explored the efficacy of sorafenib as adjuvant treatment for preventing $\mathrm{HCC}$ recurrence after surgical resection or ablation, but it failed to demonstrate a better efficacy in terms of recurrence-free survival. ${ }^{57}$ On the other hand, the phase 3 Sorafenib or Placebo in Combination with Transarterial Chemoembolization (known as the SPACE trial), failed to demonstrate a longer time to progression (TTP) in the sorafenib arm (compared to placebo) after doxorubicin-eluting beads TACE. ${ }^{58}$

To date, new treatments are clearly needed as alternatives to sorafenib or for administration after sorafenib failure.

\section{Other first-line promises}

Despite a vast number of trials studying new possible therapies for advanced HCC, almost all phase 3 trials failed to show better outcomes than sorafenib in the first-line setting (Table 1$) ;^{59-62}$ consequently, no other systemic treatments are approved for advanced HCC. Only two drugs are still being tested in phase 3 trials compared in first-line to sorafenib in advanced HCC. The first one is lenvatinib, an antiangiogenic small molecule, and the second one is nivolumab, an immune check-point inhibitor (see below).

\section{Lenvatinib}

Lenvatinib is an oral multikinase inhibitor targeting VEGF1-3, fibroblast growth factor receptors 1-4 (FGFR1-4), RET, c-kit, stem cell growth factor receptor (SCGFR) and PDGFR $\alpha$. It has antiangiogenic and direct antitumor activity. ${ }^{63}$ According to results of two large randomized trails (phase 3 and 2) ) $^{64,65}$ it has been recently approved by the Food and Drug Administration (FDA) for the treatment of adult patients with radioactive iodine refractory thyroid carcinoma and for adult patients with advanced renal cell carcinoma who have been previously treated with VEGF inhibitor. In the latter case, it is combined with everolimus. The most common side effects are those of other antiangiogenic drugs: hypertension, fatigue, proteinuria, nausea, decreased weight, abdominal pain, and HFSR.

For advanced HCC, a phase 2, single-arm, open-label multicenter study was conducted. ${ }^{66}$ Forty-six patients were enrolled at sites across Japan and Korea; the primary endpoint, median TTP, was 7.4 months (95\% CI: 5.5-9.4). Seventeen patients $(37 \%)$ reported partial response (PR) and 19 patients (41\%) had stable disease (SD) according to Response Evaluation Criteria in Solid Tumors (RECIST) version 1.1. ${ }^{67}$ The median OS was 18.7 months (95\% CI: 12.7-25.1). Moving forward based on these positive results, a multicenter, randomized, open-label, sorafenib controlled, non-inferiority phase 3 trial was planned and performed in patients affected with unresectable HCC. ${ }^{68}$ That trial is ongoing but no longer recruiting, and therefore it is possible that results will be available in the near future.

\section{Second-line therapies}

Among second-line attempts to overcome sorafenib failure, many drugs have themselves failed (Table 2). In particular, brivanib, a selective dual inhibitor of VEGFR and FGFR tyrosine kinases, did not show in the phase 3 BRISK-PS study ${ }^{69}$ a significant gain in survival compared to placebo (9.4 vs 8.2 months, HR: $0.89 ; 95.8 \% \mathrm{CI}: 0.69$ to $1.15 ; p=0.3307$ ), despite a longer TTP (4.2 vs 2.7 months; HR: $0.56 ; 95 \%$ CI: 0.42 to $0.76 ; p<0.001)$ and a greater overall response rate (ORR) ( $10 \%$ vs $2 \%$, Odds ratio: 5.72 ) according to mRECIST criteria. ${ }^{70}$ In the same way, everolimus, an mTOR inhibitor, and erlotinib, an EGFR inhibitor, did not demonstrate the ability to prolong OS compared to placebo in patients progressing during sorafenib treatment or who were intolerant to the drug. ${ }^{62,71}$

A peculiar interest is still present for ramucirumab. It is an intravenous recombinant immunoglobulin (Ig)G1 monoclonal antibody directed against VEGFR-2. ${ }^{72}$ Efficacy and safety in the HCC setting have been largely tested in a phase 3, randomized, placebo-controlled, double-blind, multicenter trial (known as REACH). ${ }^{73}$ Eligible patients were adult patients with advanced HCC who had previously stopped sorafenib due to progression or intolerance. Five-hundred-and-sixtyfive patients were enrolled, of whom 283 were assigned to the ramucirumab group and 282 were assigned to the 
Rinninella E. et al: Chemotherapy for HCC

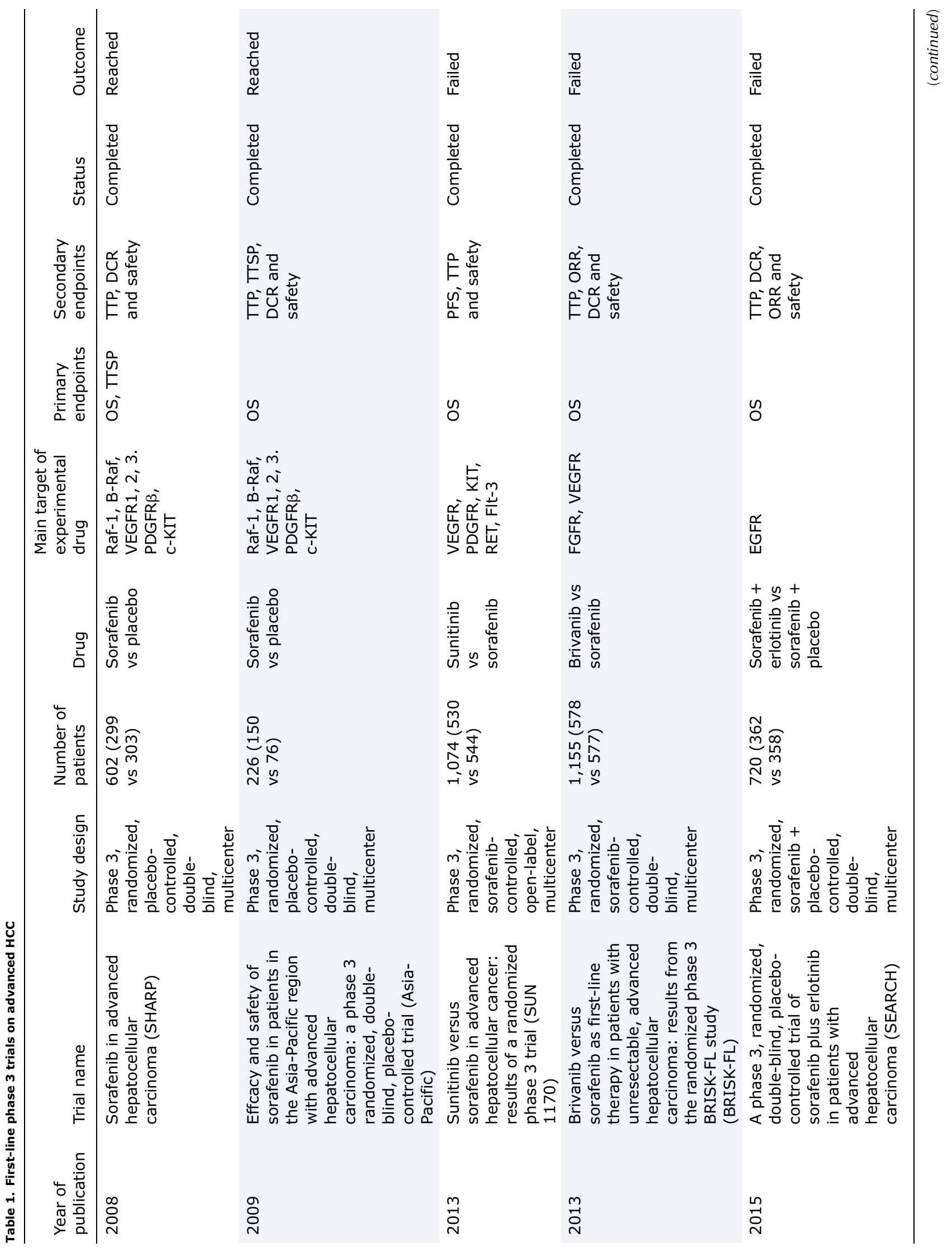




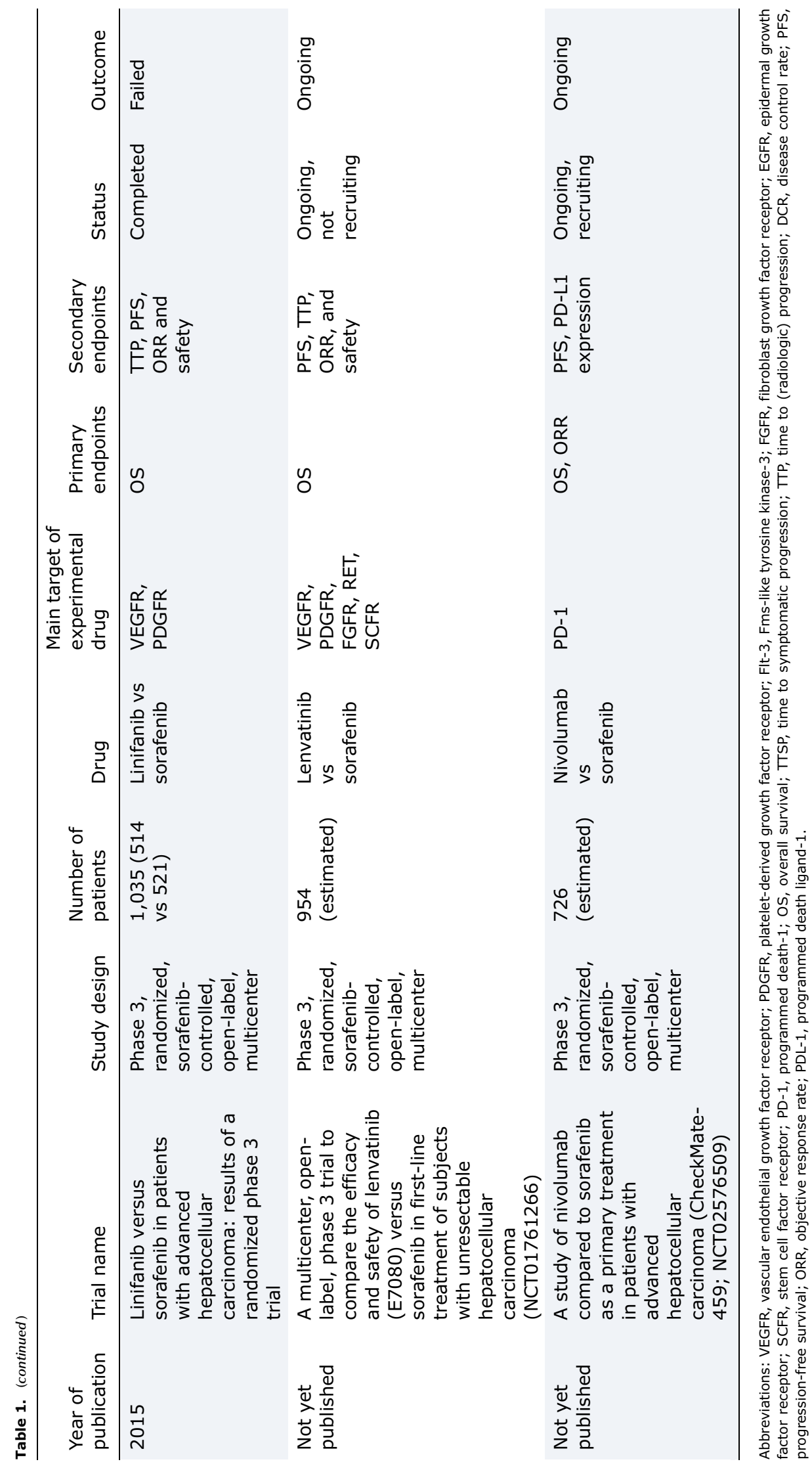


Rinninella E. et al: Chemotherapy for HCC

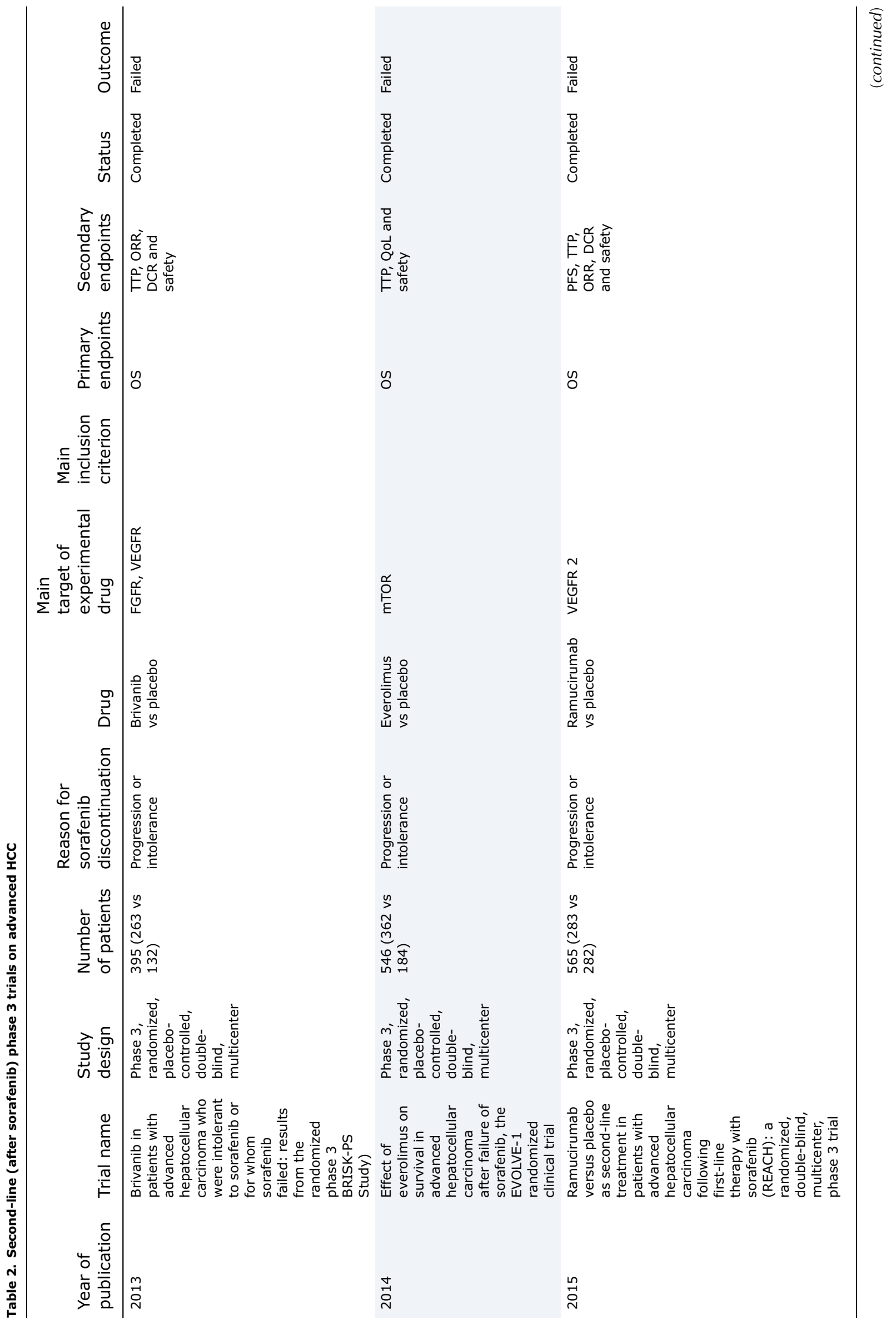


Rinninella E. et al: Chemotherapy for HCC

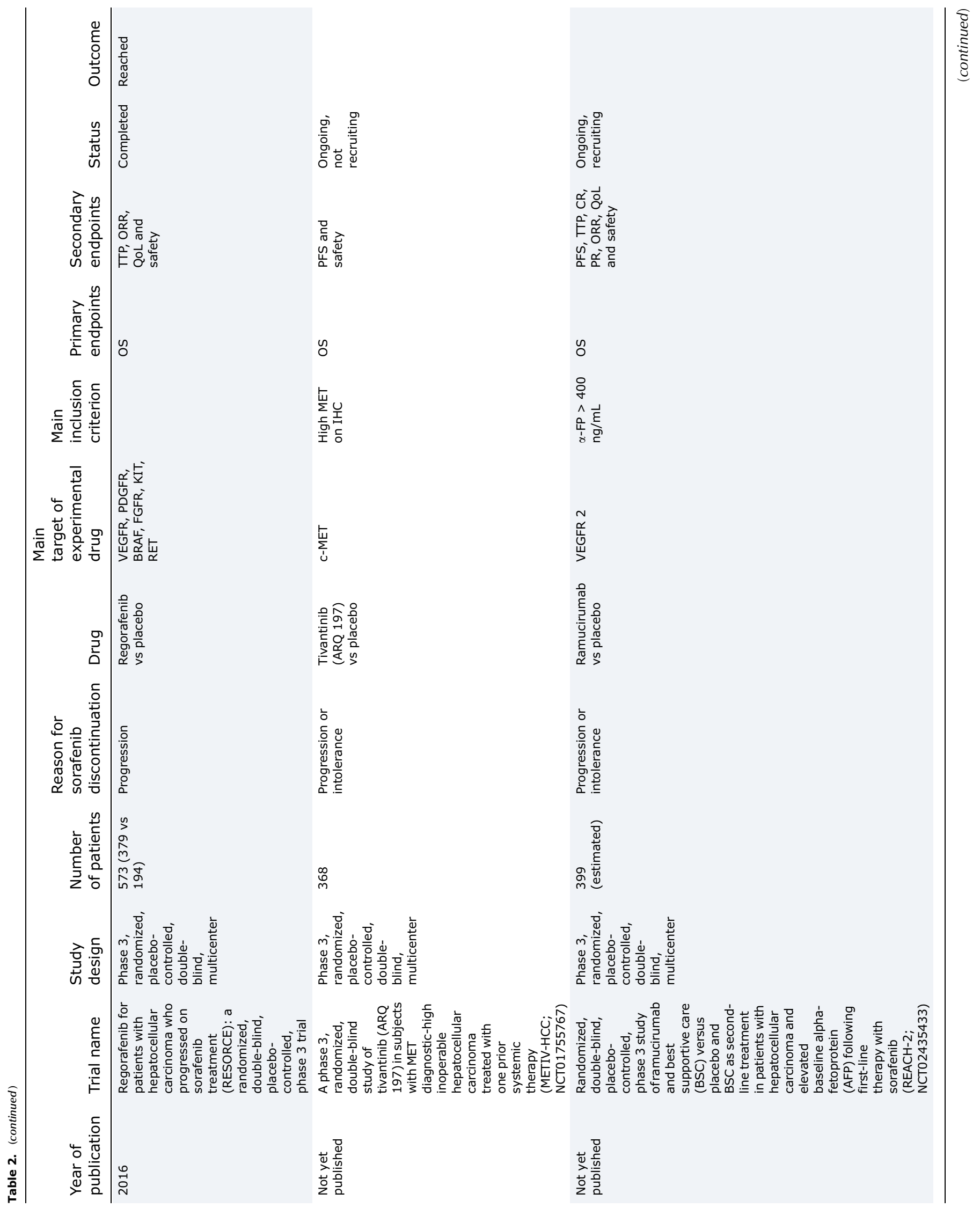


Rinninella E. et al: Chemotherapy for HCC

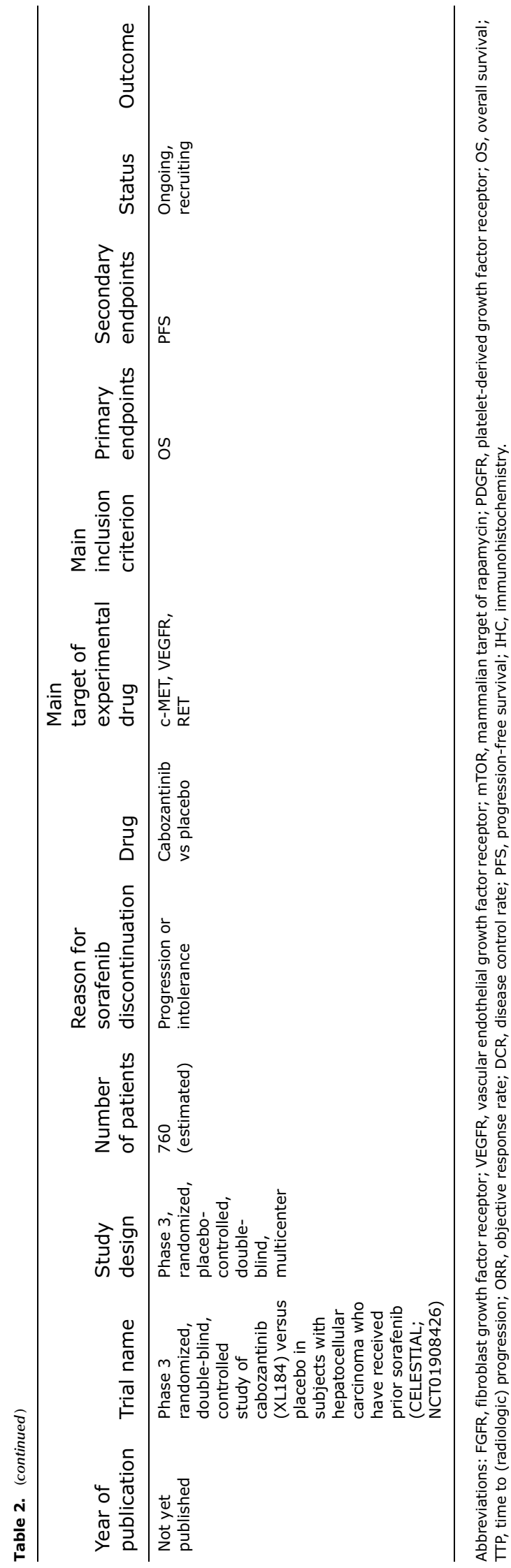

placebo group. The median OS gain in the ramucirumab group did not reach statistical significance versus the placebo arm (9.2 vs 7.6 months, HR: $0.87,95 \% \mathrm{CI}: 0.72-1.05$; $p=0.14)$. The safety profile was manageable; the most frequent treatment-emergent serious AE (grade 3 or more) was malignant neoplasm progression (6\% in the ramucirumab group vs $4 \%$ in the placebo group). In a subgroup analysis of patients with Child A functional status and baseline $\alpha$-fetoprotein $(\alpha \mathrm{FP}$ ) levels of $400 \mathrm{ng} / \mathrm{mL}$ or more, patients who received ramucirumab did achieve significantly longer OS compared with those who received placebo (for Child A5 patients, HR was $0.61,95 \% \mathrm{CI}: 0.43-0.87 ; p=0.01) .{ }^{74}$ This result provided the clinical basis for planning another phase 3 trial (titled as REACH-2), recruiting patients who progressed or are intolerant to sorafenib with a baseline $\alpha \mathrm{FP}$ of $400 \mathrm{ng} / \mathrm{mL}$ or more. The trial is now ongoing and recruiting patients. ${ }^{75}$ The estimated study completion date is April 2018.

Recently, positive results from a large phase 3 study on regorafenib have been published. ${ }^{76}$ Regorafenib is an oral multikinase inhibitor, pharmacologically similar but more potent than sorafenib, that blocks kinases involved in angiogenesis (VEGFR1-3 and TIE2), oncogenesis (c-kit, Ret and wild-type and V600-mutated BRAF) and the tumor microenvironment (PDGFR and FGFR). ${ }^{77}$ It is actually approved as monotherapy for the treatment of refractory metastatic colorectal cancer and gastrointestinal stromal tumor. ${ }^{78}$ In the RESORCE study, ${ }^{76}$ a randomized, double-blind, placebocontrolled, phase 3 trial, 567 patients affected by HCC were randomized to receive regorafenib $(n=374)$ or placebo $(n=193)$ after sorafenib failure for progression (patients stopping sorafenib for AEs were not included). Regorafenib was demonstrated to be effective in improving OS as second-line therapy (10.6 vs 7.8 months in the placebo arm; HR 0.63, 95\% CI: 0.50-0.79; $p<0.0001)$. Regorafenib also reached the secondary endpoints of PFS (HR $0.46,95 \%$ CI: $0.37-0.56 ; p<0.0001)$ and TTP (HR: $0.44,95 \% \mathrm{CI}$ : $0.36-0.55 ; p<0.0001)$. The safety profile appears similar to that of the other antiangiogenic drugs, with the most common grade 3 or 4 AEs being hypertension (15\% in the regorafenib group vs $5 \%$ in the placebo group), HFSR (13\% vs $1 \%$ ), fatigue ( $9 \%$ vs $5 \%$ ) and diarrhea ( $3 \%$ vs $0 \%$ ). Regorafenib is hence a new tool in the systemic therapy for HCC after failure of sorafenib therapy. Nevertheless, it has not been tested in patients stopping sorafenib for AEs, in whom it could be scarcely tolerated.

Another new promising tool in second-line chemotherapy after sorafenib is tivantinib. Tivantinib is an oral selective inhibitor of c-MET. ${ }^{79}$ Positive results have been obtained from a randomized phase 2 trial, comparing tivantinib versus placebo in second-line treatment (after sorafenib failure or intolerance) in patients affected by $\mathrm{HCC}^{80}$ The trial enrolled 107 patients, including 71 patients who received tivantinib (38 at $360 \mathrm{mg}$ twice-daily and 33 at $240 \mathrm{mg}$ twice-daily) and 36 patients who received placebo. A slightly significant improvement in TTP was obtained in the tivantinib arm for the overall population; however, better outcomes were reached in terms of OS (7.2 vs 3.8 months of the placebo arm; HR: $0.38,95 \% \mathrm{CI}: 0.18-0.81 ; p=0.01)$ and TTP $(2.7$ vs 1.4 months respectively; HR: $0.43,95 \% \mathrm{CI}: 0.19-0.97$; $p=0.03$ ) in a subset of patients whose tumor tissues had an overexpression of MET at immunohistochemistry (METhigh patients). The most common grade 3 or worse AEs in the tivantinib group were neutropenia ( $14 \%$ vs none in the placebo group) and anemia ( $11 \%$ vs $0 \%$ in the placebo 
Rinninella E. et al: Chemotherapy for HCC

group). Four deaths due to tivantinib-related neutropenia were reported. Grade 3 or more neutropenia was more common in the $360 \mathrm{mg}$ twice-daily dose group than in $240 \mathrm{mg}$ twice-daily group ( $21 \%$ vs $6 \%$ respectively). Given the survival benefit in the MET-high population, two large randomized, double-blind, placebo-controlled phase 3 studies have been designed to enroll MET-high inoperable HCC patients in Europe, America, Australia (known as the METIV-HCC) ${ }^{81}$ and Asia (known as the JET-HCC) ${ }^{82}$ The first trial is ongoing and not recruiting participants any longer, but the latter is still recruiting. The daily dosage in the tivantinib arm is $120 \mathrm{mg}$ twice-daily (total daily dose of $240 \mathrm{mg}$ ). The results will soon be available.

Another MET inhibitor is cabozantinib. Its action comprises the inhibition of numerous tyrosine kinase receptors as well, such as VEGFR2, KIT, RET, FLT3 and Tie-2. ${ }^{83}$ Cabozantinib was tested in the HCC setting, after a first antiangiogenic therapy failure, in a phase 2 study. ${ }^{84}$ The treatment showed effectiveness in reaching a PFS of 4.2 months with an overall disease control rate (DCR) at week 12 of $68 \%$. To date, a phase 3, placebo-controlled trial is ongoing in patients with HCC progressing during sorafenib therapy or showing intolerance to the drug. ${ }^{85}$ The study is estimated to enroll 760 patients and it could offer results in the next months.

\section{Immune checkpoint inhibitors in HCC: a look} into the future

Moving forward, a great interest has spread in anticancer therapy on the so-called "immune check-point inhibitors". The liver is a "tolerogenic" organ, expecting to receive a large amount of antigens absorbed from the gut. This tolerance is mediated by immunosuppressive cell populations, such as T regulatory cells (Tregs), myeloid-derived suppressor cells and antigen presenting cells (APCs). Among these, there are Kuppfer cells, macrophages and modulatory dendritic cells. ${ }^{86}$ Notably, the high number of these immunomodulatory cells in $\mathrm{HCC}$ tissue is correlated with disease progression and worse prognosis in HCC patients. ${ }^{87}$ Some inhibitory molecules, called "immune checkpoints", have been recognized in the physiologic maintenance of tolerance. The most cited are "programmed cell Death protein 1" (PD-1) and "cytotoxic T lymphocyte antigen-4" (CTLA-4).

PD-1 is a cell surface receptor of the Ig superfamily, expressed on T cells, $B$ cells, and natural killer cells. PD-1 binds two ligands, PD-L1 and PD-L2, expressed on APCs. The binding of PD-L1 to PD-1 transmits an inhibitory signal which reduces the proliferation of $\mathrm{CD} 8+\mathrm{T}$ cells ${ }^{88}$ and cytokine release. ${ }^{89} \mathrm{PD}-1$ also mediates immunotolerance through the differentiation and proliferation of Tregs. ${ }^{90}$ Clinical studies have shown that chronic viral infections may up-regulate the PD-1/PD-L1 pathway, leading to CD8 + T cell exhaustion and anergy. ${ }^{91}$ This suggests a role of sustained inflammation in the genesis of cancer, including HCC. In fact, a CD8+ T cell response exhaustion is a common finding in $\mathrm{HCC}$ and in both chronic HBV and HCV infection. ${ }^{92}$

CTLA-4 is a trans-membrane receptor expressed on CD4+ and CD8+ activated cells. After binding with its ligands, CD80 (also called B7-1) or CD86 (B7-2), both expressed on APCs, it transmits into the lymphocyte an inhibitory signal, contributing to the homeostatic regulation of the immune response. ${ }^{93}$ In the HCC setting, the aberrant expression of these pathways is responsible for the tumor's evasive mechanism from the immune system. ${ }^{94}$ For this reason, these two immune check-point molecules are now available for clinical evaluation.

\section{PD1- PD-L1 Blockade}

Nivolumab

Nivolumab is a genetically engineered, fully human monoclonal antibody (IgG4) directed against the negative immunoregulatory human cell surface receptor PD-1. Nivolumab binds to and blocks the activation of PD-1, inhibiting its link to PD-L1 and/or PD-L2. This results in the activation of T cells and cellmediated immune responses. ${ }^{95}$ Its action is employed in raising immune response against tumor cells or pathogens in several solid tumors.

Nivolumab is currently approved and in use in patients with metastatic melanoma, squamous non-small-cell lung cancer, advanced renal cell carcinoma, Hodgkin lymphoma and advanced metastatic squamous cell carcinoma of the head and neck. ${ }^{96}$ Nivolumab has been tested in a phase $1 / 2$ trial $^{97}$ in 47 subjects with advanced HCC ( $n=24$ uninfected; $n=12$ HCV-positive; $n=11$ HBV-positive) not amenable to curative resection. The $68 \%$ of subjects had a history of prior sorafenib exposure. The ORR (partial response+complete response) was $19 \%$ (8/42) with two subjects experiencing complete responses. The most common (frequency of $\geq 15 \%$ ) treatment-related AEs were increased serum levels of ALT, AST, lipase, amylase, and skin rash with $4 \%(2 / 47)$ of subjects withdrawn because of an AE. With the aim of confirming and evaluating efficacy and safety, there is now an ongoing randomized, open-label phase 3 trial, comparing sorafenib versus nivolumab as first-line therapy in advanced HCC (known as CheckMate-459). ${ }^{98}$ An estimated 726 patients affected by advanced HCC are randomized $1: 1$ to receive nivolumab or sorafenib until disease progression or unacceptable toxicity. CheckMate-459 started in November 2015, and the estimated primary completion date is May 2017. Primary objectives are OS and TTP. Secondary objectives include ORR, PFS and evaluation of the relationship between PD-L1 expression and efficacy.

\section{Durvalumab}

Durvalumab (MEDI4736) is a human IgG1 monoclonal antibody directed against human PD-L1. The first study in humans has been a phase 1, multicenter, open-label study, conducted in adult subjects with advanced solid tumors refractory to standard therapies or for which no standard therapies exist. ${ }^{99}$ In this cohort, a total of $21 \mathrm{HCC}$ patients were included. Patients received durvalumab every 2 weeks for a median of 6 doses. The safety profile was acceptable, with only 2 subjects (10\%) experiencing grade 3 or higher treatment-related AEs. Regarding efficacy, $21 \%$ of patients demonstrated a prolonged SD ( $\geq 3$ months) and there were no ORs. A phase 2 study to evaluate safety, antitumor activity and pharmacology of durvalumab in monotherapy or combination with tremelimumab, an anti CTLA-4 inhibitor (see above), is currently recruiting participants. ${ }^{100}$

\section{Pembrolizumab}

Pembrolizumab is a highly selective, humanized monoclonal Ig against PD-1. In a recent case report, it showed a surprising efficacy in a patient with a HCC extrahepatic 
mass non-responsive to sorafenib therapy, in absence of significant AEs. ${ }^{101}$ To date, an open-label, single-center, single-arm phase 2 trial is ongoing to evaluate efficacy and safety of pembrolizumab in advanced HCC patients who progressed or are intolerant to a first-line of antiangiogenic therapy. ${ }^{102}$

\section{CTLA-4 Blockade}

\section{Ipilimumab}

Ipilimumab is a fully humanized anti-CTLA-4 IgG1 antibody, approved for treating unresectable or metastatic melanoma in $2011 .{ }^{103}$ In the HCC setting, ipilimumab is currently being tested for safety and efficacy (ORR) combined to nivolumab in patients who are naïve to systemic therapy, using a cohort of a phase $1 / 2$ trial. $^{104}$

\section{Tremelimumab}

Tremelimumab is a human IgG2 monoclonal antibody specific for human CTLA-4. Tremelimumab blocks the inhibitory effect of CTLA-4, and therefore enhances $T$ cell activation. In a pivotal study, conducted on a small number of patients affected by HCV cirrhosis-related HCC, it showed an acceptable safety profile, both anti-viral and anti-tumor activities (PR: $17.6 \%$, SD: $58.8 \%){ }^{105}$ A recent study by Duffy et al. ${ }^{100}$ demonstrated that tremelimumab in combination with tumor ablation leads to the accumulation of intratumoral CD8+ T cells. ${ }^{106} \mathrm{~A}$ phase 2 trial testing tremelimumab combined with durvalumab or in monotherapy on patients affected by unresectable HCC with or without HBV or HCV infection, is ongoing and enrolling patients.

\section{The role of branched-chain amino acids (BCAAs) in HCC setting}

An important reason for the poor prognosis of patients with $\mathrm{HCC}$ is the liver function failure, caused by underlying cirrhosis. ${ }^{21,25}$ This condition leads to protein-energy malnutrition, due to poor appetite and disorders in protein synthesis, and it is associated with high morbidity and mortality. ${ }^{107}$ Furthermore, patients with liver cancer often have increased protein catabolism; a significant proportion of HCC patients are malnourished or at risk of malnutrition, and this represents a negative prognostic value in the survival outcome. ${ }^{108}$

The BCAAs valine, leucine and isoleucine are essential amino acids with aliphatic branched side chains. Besides constituting proteins, they are a source of glutamate, which detoxifies ammonia through glutamine synthesis in skeletal muscle. ${ }^{109}$ This property is usually exploited in treating hepatic encephalopathy, as recommended by international guidelines. ${ }^{110}$ The BCAA reduction is an important hallmark of liver cirrhosis. Several studies demonstrate that BCAA supplementation improves nutritional status, prognosis and quality of life in these patients. ${ }^{111,112}$

BCAAs were also found to inhibit hepatocarcinogenesis by different means, such as the amelioration of insulin resistance and hyperinsulinemia, ${ }^{113}$ the improvement of immune function and the reduction of oxidative stress. ${ }^{114}$ In addition, BCAAs may enhance the sensitivity to chemotherapy by reducing the population of cancer stem cells, which may differentiate into cancer cells, through activation of the mTOR complex $1 .{ }^{115}$ Moreover, a lot of studies have shown the usefulness of nutritional supplementation with BCAAs in patients with HCC undergoing interventions such as surgery, RFA or TACE. ${ }^{116-118}$

Takeda et al. ${ }^{119}$ performed a retrospective cohort study exploring the effect of BCAA therapy (952 mg of L-isoleucine, $1904 \mathrm{mg}$ of L-leucine and $1144 \mathrm{mg}$ of L-valine given three times daily after meals) in patients with unresectable HCC treated with sorafenib. The study showed that OS and the median administration period of sorafenib in the BCAA group were significantly longer than those in the control group ( $p=$ 0.020 and $p=0.004$ respectively). Moreover, after 3 months, albumin levels in the control group decreased significantly compared with pretreatment value $(p=0.009)$, whereas in the BCAA group there was not a significant decrease from baseline $(p=0.76)$; this suggests a role for BCAA in the maintenance of albumin levels during sorafenib therapy.

A recent meta-analysis, ${ }^{120}$ including 11 interventional studies (surgical or non-surgical procedures) on HCC found that BCAA-supplemented groups had better outcomes in terms of survival, albumin levels and lower risk of liver decompensation. In particular, 3-year mortality was statistically lower in the BCAA groups than in the control groups ( $37 \%$ vs $44 \%$, $p=0.012$ ), whereas the 1 -year survival gain did not reach statistical significance ( $18 \%$ vs $21 \%, p=0.214$ ). The survival benefit was more evident in Child $\mathrm{B}$ patients, confirming a possible role of BCAA in the maintenance of metabolic homeostasis in moderately decompensated liver cirrhosis.

Thus, oral BCAA supplementation is probably useful for maintaining hepatic functional reserve in HCC patients. BCAA use could avoid early discontinuance of therapy and improve OS in patients with HCC treated with sorafenib, provided that a correct dosage is administered.

\section{Conclusions}

After the revolution brought about by sorafenib introduction into clinical practice, patients with advanced HCC have been included in a large number of clinical trials, many of which have yielded non-significant results. In the first-line setting, we are waiting for the result of a lenvatinib phase 3 trial. In second-line field, several antiangiogenic drugs have failed to demonstrate a gain of efficacy in terms of survival. The recent positive results achieved with regorafenib have opened new possibilities in the treatment of patients who progressed on sorafenib. Considerable efforts are being invested in the socalled "immune check-point blockade", that is considered the new frontier of the treatment of many solid tumors. A phase 3 trial is already testing nivolumab compared to sorafenib as first-line in HCC patients. BCAAs and nutritional support will almost certainly play a role in HCC treatment, given their effect in the maintenance of a good nutritional and functional status and the possibility of an intrinsic antineoplastic activity. Maybe in the next future, it will be possible to combine conventional HCC treatments with other targeted-molecules and immune check-point inhibitors, in order to obtain a more effective control of the disease and an improvement of OS; this could be especially obtained in those patients who have progressed during sorafenib or who are intolerant to the drug.

\section{Conflict of interest}

The authors have no conflict of interests related to this publication. 


\section{Author contributions}

Conceived the topic (ER), prepared the manuscript (ER, LC), generated the schematic diagrams (ER, LC, IS, MC), contributed to nutritional section (MCM, MC, IS), edited the manuscript (MP, AG). All the authors made significant contributions to this review article.

\section{References}

[1] Ferlay J, Soerjomataram I, Dikshit R, Eser S, Mathers C, Rebelo M, et al. Cancer incidence and mortality worldwide: sources, methods and major patterns in GLOBOCAN 2012. Int J Cancer 2015;136:E359-E386. doi: $10.1002 /$ ijc. 29210.

[2] Parkin DM, Bray F, Ferlay J, Pisani P. Global cancer statistics, 2002. CA Cancer J Clin 2005;55:74-108. doi: 10.3322/canjclin.55.2.74.

[3] Tanaka H, Imai Y, Hiramatsu N, Ito Y, Imanaka K, Oshita M, et al. Declining incidence of hepatocellular carcinoma in Osaka, Japan, from 1990 to 2003. Ann Intern Med 2008;148:820-826. doi: 10.7326/0003-4819-148-11200806030-00004.

[4] Bosetti C, Levi F, Boffetta P, Lucchini F, Negri E, La Vecchia C. Trends in mortality from hepatocellular carcinoma in Europe, 1980-2004. Hepatology 2008;48:137-145. doi: 10.1002/hep.22312.

[5] Llovet JM, Burroughs A, Bruix J. Hepatocellular carcinoma. Lancet 2003; 362:1907-1917. doi: 10.1016/S0140-6736(03)14964-1.

[6] Beasley RP, Hwang LY, Lin CC, Chien CS. Hepatocellular carcinoma and hepatitis B virus. A prospective study of 22707 men in Taiwan. Lancet 1981;2: 1129-1133. doi: 10.1016/S0140-6736(81)90585-7.

[7] El-Serag HB. Hepatocellular carcinoma. N Engl J Med 2011;365: 1118-1127. doi: $10.1056 /$ NEJMra1001683.

[8] Thorgeirsson SS, Grisham JW. Molecular pathogenesis of human hepatocellular carcinoma. Nat Genet 2002;31:339-346. doi: 10.1038/ng0802-339.

[9] Siegel AB, Olsen SK, Magun A, Brown RS Jr. Sorafenib: where do we go from here? Hepatology 2010;52:360-369. doi: 10.1002/hep.23633.

[10] Hsu IC, Metcalf RA, Sun T, Welsh JA, Wang NJ, Harris CC. Mutational hotspot in the p53 gene in human hepatocellular carcinomas. Nature $1991 ; 350$ 427-428. doi: $10.1038 / 350427 a 0$.

[11] Villa E, Melegari M, Scaglioni PP, Trande P, Cesaro P, Manenti F. Hepatocellular carcinoma: risk factors other than HBV. Ital J Gastroenterol 1991;23: 457-460.

[12] Peck-Radosavljevic M. Hepatocellular carcinoma: the place of new medica therapies. Therap Adv Gastroenterol 2010;3:259-267. doi: 10.1177/ $1756283 \times 10362278$

[13] Deugnier YM, Guyader D, Crantock L, Lopez JM, Turlin B, Yaouanq J, et al. Primary liver cancer in genetic hemochromatosis: a clinical, pathological and pathogenetic study of 54 cases. Gastroenterology $1993 ; 104: 228-234$ doi: 10.1016/0016-5085(93)90856-8.

[14] Perlmutter DH. Pathogenesis of chronic liver injury and hepatocellular carcinoma in alpha-1-antitrypsin deficiency. Pediatr Res 2006;60:233-238. doi: 10.1203/01.pdr.0000228350.61496.90.

[15] Polio J, Enriquez RE, Chow A, Wood WM, Atterbury CE. Hepatocellular carcinoma in Wilson's disease. Case report and review of the literature. J Clin Gastroenterol 1989;11:220-224. doi: 10.1097/00004836-19890400000022.

[16] Dyal HK, Aguilar M, Bhuket T, Liu B, Holt EW, Torres S, et al. Concurrent obesity, diabetes, and steatosis increase risk of advanced fibrosis among HCV patients: a systematic review. Dig Dis Sci 2015;60:2813-2824. doi: 10.1007/s10620-015-3760-3

[17] Yang WS, Va P, Bray F, Gao S, Gao J, Li HL, Xiang YB. The role of pre-existing diabetes mellitus on hepatocellular carcinoma occurrence and prognosis: meta-analysis of prospective cohort studies. PLoS One 2011;6:e27326. doi: 10.1371/journal.pone.0027326.

[18] Hung $\mathrm{CH}$, Wang $\mathrm{JH}$, $\mathrm{Hu} \mathrm{TH}$, Chen $\mathrm{CH}$, Chang $\mathrm{KC}$, Yen $\mathrm{YH}$, et al. Insulin resistance is associated with hepatocellular carcinoma in chronic hepatitis C infection. World J Gastroenterol 2010;16:2265-2271. doi: 10.3748/wjg. v16.i18.2265.

[19] Marrero JA, Fontana RJ, Fu S, Conjeevaram HS, Su GL, Lok AS. Alcohol, tobacco and obesity are synergistic risk factors for hepatocellular carcinoma. J Hepatol 2005;42:218-224. doi: 10.1016/j.jhep.2004.10.005.

[20] Ampuero J, Romero-Gomez M. Prevention of hepatocellular carcinoma by correction of metabolic abnormalities: Role of statins and metformin. World J Hepatol 2015;7:1105-1111. doi: 10.4254/wjh.v7.i8.1105.

[21] European Association for the Study of the Liver; European Organisation for Research and Treatment of Cancer. EASL-EORTC clinical practice guidelines: management of hepatocellular carcinoma. J Hepatol 2012;56:908-943. doi: 10.1016/j.jhep.2011.12.001.
[22] Mazzaferro V, Regalia E, Doci R, Andreola S, Pulvirenti A, Bozzetti F, et al. Liver transplantation for the treatment of small hepatocellular carcinomas in patients with cirrhosis. N Engl J Med 1996;334:693-699. doi: 10.1056/ NEJM199603143341104.

[23] Mazzaferro V, Llovet JM, Miceli R, Bhoori S, Schiavo M, Mariani L, et al. Predicting survival after liver transplantation in patients with hepatocellular carcinoma beyond the Milan criteria: a retrospective, exploratory analysis. Lancet Oncol 2009;10:35-43. doi: 10.1016/S1470-2045(08)70284-5.

[24] Yao FY, Ferrell L, Bass NM, Watson J], Bacchetti P, Venook A, et al. Liver transplantation for hepatocellular carcinoma: expansion of the tumor size limits does not adversely impact survival. Hepatology 2001;33:13941403. doi: 10.1053/jhep.2001.24563.

[25] Bruix J, Sherman M, American Association for the Study of Liver Diseases. Management of hepatocellular carcinoma: an update. Hepatology 2011;53: 1020-1022. doi: 10.1002/hep.24199.

[26] Kudo M, Izumi N, Kokudo N, Matsui O, Sakamoto M, Nakashima O, et al. Management of hepatocellular carcinoma in Japan: Consensus-Based Clinical Practice Guidelines proposed by the Japan Society of Hepatology (JSH) 2010 updated version. Dig Dis 2011;29:339-364. doi: 10.1159/000327577.

[27] Llovet JM, Ricci S, Mazzaferro V, Hilgard P, Gane E, Blanc JF, et al. Sorafenib in advanced hepatocellular carcinoma. N Engl J Med 2008;359:378-390. doi: $10.1056 /$ NEJMoa0708857.

[28] Jelic S, Sotiropoulos GC, ESMO Guidelines Working Group. Hepatocellular carcinoma: ESMO Clinical Practice Guidelines for diagnosis, treatment and follow-up. Ann Oncol 2010;21 Suppl 5:v59-v64. doi: 10.1093/annonc/ mdq166.

[29] National comprehensive cancer network clinical practice guidelines in oncology. Hepatobiliary guidelines. V2. 2010. Available from: http://www.nccn. org/professionals/physician_gls/PDF/hepatobiliary.pdf, accessed December 2016.

[30] Kulik LM, Atassi B, van Holsbeeck L, Souman T, Lewandowski RJ, Mulcahy $\mathrm{MF}$, et al. Yttrium-90 microspheres (TheraSphere) treatment of unresectable hepatocellular carcinoma: downstaging to resection, RFA and bridge to transplantation. J Surg Oncol 2006;94:572-586. doi: 10.1002/jso.20609.

[31] Deng GL, Zeng S, Shen H. Chemotherapy and target therapy for hepatocellular carcinoma: New advances and challenges. World J Hepatol 2015;7: 787-798. doi: 10.4254/wjh.v7.i5.787.

[32] Tian Y, Mok MT, Yang P, Cheng AS. Epigenetic activation of wnt $/ \beta$-catenin signaling in NAFLD-associated hepatocarcinogenesis. Cancers (Basel) 2016;8: pii, E76. doi: 10.3390/cancers8080076.

[33] Llovet JM, Villanueva A, Lachenmayer A, Finn RS. Advances in targeted therapies for hepatocellular carcinoma in the genomic era. Nat Rev Clin Oncol 2015;12:408-424. doi: 10.1038/nrclinonc.2015.103.

[34] Chen C, Wang G. Mechanisms of hepatocellular carcinoma and challenges and opportunities for molecular targeted therapy. World J Hepatol 2015;7: 1964-1970. doi: 10.4254/wjh.v7.i15.1964.

[35] Alexia C, Bras M, Fallot G, Vadrot N, Daniel F, Lasfer M, et al. Pleiotropic effects of PI-3' kinase/Akt signaling in human hepatoma cell proliferation and drug-induced apoptosis. Ann N Y Acad Sci 2006;1090:1-17. doi: 10.1196/ annals.1378.001.

[36] Villanueva A, Chiang DY, Newell P, Peix J, Thung S, Alsinet C, et al. Pivotal role of mTOR signaling in hepatocellular carcinoma. Gastroenterology 2008;135:1972-1983, 1983.e1-e11. doi: 10.1053/j.gastro.2008.08.008.

[37] Horie Y, Suzuki A, Kataoka E, Sasaki T, Hamada K, Sasaki J, et al. Hepatocytespecific Pten deficiency results in steatohepatitis and hepatocellular carcinomas. J Clin Invest 2004;113:1774-1783. doi: 10.1172/JCI20513.

[38] Sabatini DM. mTOR and cancer: insights into a complex relationship. Nat Rev Cancer 2006;6:729-734. doi: 10.1038/nrc1974.

[39] Yoshiji H, Kuriyama S, Yoshii ], Yamazaki M, Kikukawa M, Tsujinoue H, et al. Vascular endothelial growth factor tightly regulates in vivo development of murine hepatocellular carcinoma cells. Hepatology 1998;28:1489-1496. doi: $10.1002 /$ hep.510280607.

[40] Moon WS, Rhyu KH, Kang MJ, Lee DG, Yu HC, Yeum JH, et al. Overexpression of VEGF and angiopoietin 2: a key to high vascularity of hepatocellular carcinoma? Mod Pathol 2003;16:552-557. doi: 10.1097/01.MP.0000071841. 17900.69.

[41] Wada $\mathrm{H}$, Nagano $\mathrm{H}$, Yamamoto $\mathrm{H}$, Yang $\mathrm{Y}$, Kondo $M$, Ota $\mathrm{H}$, et al. Expression pattern of angiogenic factors and prognosis after hepatic resection in hepatocellular carcinoma: importance of angiopoietin-2 and hypoxia-induced factor-1 alpha. Liver Int 2006;26:414-423. doi: 10.1111/j.1478-3231. 2006.01243.x.

[42] Poon RT, Lau C, Pang R, Ng KK, Yuen ], Fan ST. High serum vascular endothelial growth factor levels predict poor prognosis after radiofrequency ablation of hepatocellular carcinoma: importance of tumor biomarker in ablative therapies. Ann Surg Oncol 2007;14:1835-1845. doi: 10.1245/s10434007-9366-z.

[43] Conway EM, Collen D, Carmeliet P. Molecular mechanisms of blood vessel growth. Cardiovasc Res 2001;49:507-521. doi: 10.1016/S0008-6363(00) 00281-9. 
[44] Huynh H. Molecularly targeted therapy in hepatocellular carcinoma. Biochem Pharmacol 2010 Sep 1;80:550-560. doi: 10.1016/j.bcp.2010. 03.034.

[45] Komposch K, Sibilia M. EGFR Signaling in Liver Diseases. Int J Mol Sci 2015; 17. pii: E30. doi: 10.3390/ijms 17010030 .

[46] Berasain C, Nicou A, Garcia-Irigoyen O, Latasa MU, Urtasun R, Elizalde M, et al. Epidermal growth factor receptor signaling in hepatocellular carcinoma: inflammatory activation and a new intracellular regulatory mechanism. Dig Dis 2012;30:524-531. doi: 10.1159/000341705.

[47] Li YL, Zheng MX, Wang G. A personalized approach identifies disturbed pathways and key genes in hepatitis $C$ virus-cirrhosis with hepatocellular carcinoma. Eur Rev Med Pharmacol Sci 2016;20:4266-4273.

[48] Venepalli NK, Goff L. Targeting the HGF-CMET axis in hepatocellular carcinoma. Int J Hepatol 2013;2013:341636. doi: 10.1155/2013/341636.

[49] Wilhelm SM, Carter C, Tang L, Wilkie D, McNabola A, Rong H, et al. BAY 43-9006 exhibits broad spectrum oral antitumor activity and targets the RAF/MEK/ERK pathway and receptor tyrosine kinases involved in tumor progression and angiogenesis. Cancer Res 2004;64:7099-7109. doi: 10. 1158/0008-5472.CAN-04-1443.

[50] Cheng AL, Kang YK, Chen Z, Tsao CJ, Qin S, Kim JS, et al. Efficacy and safety of sorafenib in patients in the Asia-Pacific region with advanced hepatocellular carcinoma: a phase III randomised, double-blind, placebo-controlled trial. Lancet Oncol 2009;10:25-34. doi: 10.1016/S1470-2045(08)70285-7.

[51] Iavarone M, Cabibbo G, Piscaglia F, Zavaglia C, Grieco A, Villa E, et al. Fieldpractice study of sorafenib therapy for hepatocellular carcinoma: a prospective multicenter study in Italy. Hepatology 2011;54:2055-2063. doi: 10. 1002/hep. 24644

[52] Marrero JA, Kudo M, Venook AP, Ye SL, Bronowicki JP, Chen XP, et al. Observational registry of sorafenib use in clinical practice across Child-Pugh subgroups: The GIDEON study. J Hepatol 2016;65:1140-1147. doi: 10.1016/j. jhep.2016.07.020.

[53] Nishikawa H, Osaki Y, Endo M, Takeda H, Tsuchiya K, Joko K, et al. Comparison of standard-dose and half-dose sorafenib therapy on clinical outcome in patients with unresectable hepatocellular carcinoma in field practice: A propensity score matching analysis. Int J Oncol 2014;45:2295-2302. doi: 10.3892/ijo.2014.2654.

[54] Vincenzi B, Santini D, Russo A, Addeo R, Giuliani F, Montella L, et al. Early skin toxicity as a predictive factor for tumor control in hepatocellular carcinoma patients treated with sorafenib. Oncologist 2010;15:85-92. doi: 10.1634/theoncologist.2009-0143.

[55] Bettinger D, Schultheiss M, Knüppel E, Thimme R, Blum HE, Spangenberg HC. Diarrhea predicts a positive response to sorafenib in patients with advanced hepatocellular carcinoma. Hepatology 2012;56:789-790. doi: 10.1002/hep. 25637.

[56] Schoenleber S], Kurtz DM, Talwalkar JA, Roberts LR, Gores GJ. Prognostic role of vascular endothelial growth factor in hepatocellular carcinoma: systematic review and meta-analysis. Br J Cancer 2009;100:1385-1392. doi: $10.1038 /$ sj.bjc. 6605017.

[57] Bruix J, Takayama T, Mazzaferro V, Chau GY, Yang J, Kudo M, et al. Adjuvant sorafenib for hepatocellular carcinoma after resection or ablation (STORM): a phase 3, randomised, double-blind, placebo-controlled trial. Lancet Oncol 2015;16:1344-1354. doi: 10.1016/S1470-2045(15)00198-9.

[58] Lencioni R, Llovet JM, Han G, Tak WY, Yang J, Guglielmi A, et al. Sorafenib or placebo plus TACE with doxorubicin-eluting beads for intermediate stage HCC: The SPACE trial. J Hepatol 2016;64:1090-1098. doi: 10.1016/j. jhep.2016.01.012.

[59] Cheng AL, Kang YK, Lin DY, Park JW, Kudo M, Qin S, et al. Sunitinib versus sorafenib in advanced hepatocellular cancer: results of a randomized phase III trial. J Clin Oncol 2013;31:4067-4075. doi: 10.1200/JCO.2012.45. 8372.

[60] Johnson PJ, Qin S, Park JW, Poon RT, Raoul JL, Philip PA, et al. Brivanib versus sorafenib as first-line therapy in patients with unresectable, advanced hepatocellular carcinoma: results from the randomized phase III BRISK-FL study. J Clin Oncol 2013;31:3517-3524. doi: 10.1200/JCO. 2012.48.4410.

[61] Cainap C, Qin S, Huang WT, Chung IJ, Pan H, Cheng Y, et al. Linifanib versus Sorafenib in patients with advanced hepatocellular carcinoma: results of a randomized phase III trial. J Clin Oncol 2015;33:172-179. doi: 10. 1200/JCO.2013.54.3298.

[62] Zhu AX, Rosmorduc O, Evans TR, Ross PJ, Santoro A, Carrilho FJ, et al. SEARCH: a phase III, randomized, double-blind, placebo-controlled tria of sorafenib plus erlotinib in patients with advanced hepatocellular carcinoma. J Clin Oncol 2015;33:559-566. doi: 10.1200/JCO.2013.53.7746.

[63] Cabanillas ME, Habra MA. Lenvatinib: Role in thyroid cancer and other solid tumors. Cancer Treat Rev 2016;42:47-55. doi: 10.1016/j.ctrv.2015.11.003.

[64] Schlumberger M, Tahara M, Wirth LJ, Robinson B, Brose MS, Elisei R, et al. Lenvatinib versus placebo in radioiodine-refractory thyroid cancer. N Engl J Med 2015;372:621-630. doi: 10.1056/NEJMoa1406470.

[65] Motzer RJ, Hutson TE, Glen H, Michaelson MD, Molina A, Eisen T, et al. Lenvatinib, everolimus, and the combination in patients with metastatic renal cell carcinoma: a randomised, phase 2, open-label, multicentre trial. Lancet Oncol 2015;16:1473-1482. doi: 10.1016/S1470-2045(15)00290-9.

[66] Ikeda K, Kudo M, Kawazoe S, Osaki Y, Ikeda M, Okusaka T, et al. Phase 2 study of lenvatinib in patients with advanced hepatocellular carcinoma. J Gastroenterol 2017;52:512-519. doi: 10.1007/s00535-016-1263-4.

[67] Eisenhauer EA, Therasse P, Bogaerts J, Schwartz LH, Sargent D, Ford R, et al. New response evaluation criteria in solid tumours: revised RECIST guideline (version 1.1). Eur J Cancer 2009;45:228-247. doi: 10.1016/j. ejca.2008.10.026.

[68] A multicenter, open-label, phase 3 trial to compare the efficacy and safety of lenvatinib (E7080) versus sorafenib in first-line treatment of subjects with unresectable hepatocellular carcinoma. Available from: https://clinicaltrials.gov/ct2/show/NCT01761266, accessed March 24, 2017.

[69] Llovet JM, Decaens T, Raoul JL, Boucher E, Kudo M, Chang C, et al. Brivanib in patients with advanced hepatocellular carcinoma who were intolerant to sorafenib or for whom sorafenib failed: results from the randomized phase III BRISK-PS study. J Clin Oncol 2013;31:3509-3516. doi: 10.1200/JCO. 2012.47.3009.

[70] Lencioni R, Llovet JM. Modified RECIST (mRECIST) assessment for hepatocellular carcinoma. Semin Liver Dis 2010;30:52-60. doi: 10.1055/s-00301247132

[71] Zhu AX, Kudo M, Assenat E, Cattan S, Kang YK, Lim HY, et al. Effect of everolimus on survival in advanced hepatocellular carcinoma after failure of sorafenib: the EVOLVE-1 randomized clinical trial. JAMA 2014;312: 57-67. doi: 10.1001/jama.2014.7189.

[72] Poole RM, Vaidya A. Ramucirumab: first global approval. Drugs 2014; 74 : 1047-1058. doi: 10.1007/s40265-014-0244-2.

[73] Zhu AX, Park JO, Ryoo BY, Yen CJ, Poon R, Pastorelli D, et al. Ramucirumab versus placebo as second-line treatment in patients with advanced hepatocellular carcinoma following first-line therapy with sorafenib (REACH): a randomised, double-blind, multicentre, phase 3 trial. Lancet Oncol 2015; 16:859-870. doi: 10.1016/S1470-2045(15)00050-9.

[74] Zhu AX, Baron AD, Malfertheiner P, Kudo M, Kawazoe S, Pezet D, et al. Ramucirumab as second-line treatment in patients with advanced hepatocellular carcinoma: analysis of REACH trial results by child-pugh score. JAMA Oncol 2016. doi: 10.1001/jamaoncol.2016.4115.

[75] A study of ramucirumab (LY3009806) versus placebo in participants with hepatocellular carcinoma and elevated baseline alpha-fetoprotein (REACH-2). Available from: https://clinicaltrials.gov/ct2/show/NCT02435433, accessed May 2017.

[76] Bruix J, Qin S, Merle P, Granito A, Huang YH, Bodoky G, et al. Regorafenib for patients with hepatocellular carcinoma who progressed on sorafenib treatment (RESORCE): a randomised, double-blind, placebo-controlled, phase 3 trial. Lancet 2017;389:56-66. doi: 10.1016/S0140-6736(16)32453-9.

[77] Wilhelm SM, Dumas J, Adnane L, Lynch M, Carter CA, Schütz G, et al. Regorafenib (BAY 73-4506): a new oral multikinase inhibitor of angiogenic, stromal and oncogenic receptor tyrosine kinases with potent preclinical antitumor activity. Int J Cancer 2011;129:245-255. doi: 10.1002/ijc. 25864.

[78] Stivarga approval history. Available from: https://www.drugs.com/history/stivarga.html.

[79] Adjei AA, Schwartz B, Garmey E. Early clinical development of ARQ 197, a selective, non-ATP-competitive inhibitor targeting MET tyrosine kinase for the treatment of advanced cancers. Oncologist 2011;16:788-799. doi: 10 . 1634/theoncologist.2010-0380.

[80] Santoro A, Rimassa L, Borbath I, Daniele B, Salvagni S, Van Laethem JL, et al. Tivantinib for second-line treatment of advanced hepatocellular carcinoma: a randomised, placebo-controlled phase 2 study. Lancet Oncol 2013;14:55-63. doi: 10.1016/S1470-2045(12)70490-4.

[81] Study of tivantinib in subjects with inoperable hepatocellular carcinoma who have been treated with one prior therapy (METIV-HCC). Available from: https://www.clinicaltrials.gov/ct2/show/NCT01755767, accessed January 2016.

[82] A randomized double-blind, placebo-controlled japanese phase III trial of ARQ 197 in hepatocellular carcinoma (HCC) (JET-HCC). Available from: https://www.clinicaltrials.gov/ct2/show/NCT02029157, accessed December 2016.

[83] Fallahi P, Ferrari SM, Di Bari F, Materazzi G, Benvenga S, Miccoli P, et al. Cabozantinib in Thyroid Cancer. Recent Pat Anticancer Drug Discov 2015; 10:259-269. doi: 10.2174/1574892810666150708110816.

[84] Verslype C, Cohn AL, Kelley RK, Yang TS, Su WC, Ramies DA, et al. Activity of cabozantinib (XL184) in hepatocellular carcinoma: Results from a phase II randomized discontinuation trial (RDT). J Clin Oncol 2012;30 (suppl; abstr 4007).

[85] Study of cabozantinib (XL184) vs placebo in subjects with hepatocellular carcinoma who have received prior sorafenib (CELESTIAL). Available from: https://clinicaltrials.gov/ct2/show/NCT01908426, accessed August 2016

[86] Thomson AW, Knolle PA. Antigen-presenting cell function in the tolerogenic liver environment. Nat Rev Immunol 2010;10:753-766. doi: 10.1038/ nri2858. 
[87] Chen KJ, Lin SZ, Zhou L, Xie HY, Zhou WH, Taki-Eldin A, et al. Selective recruitment of regulatory T cell through CCR6-CCL20 in hepatocellular carcinoma fosters tumor progression and predicts poor prognosis. PLoS One 2011;6:e24671. doi: 10.1371/journal.pone.0024671.

[88] Karwacz K, Bricogne C, MacDonald D, Arce F, Bennett CL, Collins M, et al. PD-L1 co-stimulation contributes to ligand-induced T cell receptor downmodulation on CD8+ T cells. EMBO Mol Med 2011;3:581-592. doi: 10. 1002/emmm.201100165.

[89] Okazaki T, Maeda A, Nishimura H, Kurosaki T, Honjo T. PD-1 immunoreceptor inhibits $B$ cell receptor-mediated signaling by recruiting src homology 2-domain-containing tyrosine phosphatase 2 to phosphotyrosine. Proc Nat Acad Sci U S A 2001;98:13866-13871. doi: 10.1073/pnas.231486598.

[90] Wing K, Onishi Y, Prieto-Martin P, Yamaguchi T, Miyara M, Fehervari Z, et al. CTLA-4 control over Foxp3+ regulatory T cell function. Science 2008;322: 271-275. doi: 10.1126/science.1160062.

[91] Barber DL, Wherry EJ, Masopust D, Zhu B, Allison JP, Sharpe AH, et al. Restoring function in exhausted CD8 T cells during chronic viral infection. Nature 2006;439:682-687. doi: 10.1038/nature04444.

[92] Moreno-Cubero E, Larrubia JR. Specific CD8(+) T cell response immunotherapy for hepatocellular carcinoma and viral hepatitis. World J Gastroenterol 2016;22:6469-6483. doi: 10.3748/wjg.v22.i28.6469.

[93] Walunas TL, Lenschow DJ, Bakker CY, Linsley PS, Freeman GJ, Green JM, et al. CTLA-4 can function as a negative regulator of $\mathrm{T}$ cell activation. Immunity 1994;1:405-413. doi: 10.1016/1074-7613(94)90071-X.

[94] Hato T, Goyal L, Greten TF, Duda DG, Zhu AX. Immune checkpoint blockade in hepatocellular carcinoma: current progress and future directions. Hepatology 2014;60:1776-1782. doi: 10.1002/hep.27246.

[95] John LB, Devaud C, Duong CP, Yong CS, Beavis PA, Haynes NM, et al. AntiPD-1 antibody therapy potently enhances the eradication of established tumors by gene-modified T cells. Clin Cancer Res 2013;19:5636-5646. doi: $10.1158 / 1078-0432 . C C R-13-0458$.

[96] Opdivo approval history. Available from: https://www.drugs.com/history/ opdivo.html.

[97] El-Khoueiry AB, Melero I, Crocenzi TS, Welling TH, Yau TC, Yeo W, et al. Phase I/II safety and antitumor activity of nivolumab in patients with advanced hepatocellular carcinoma (HCC): CA209-040. J Clin Oncol 2015;33(suppl; abstr LBA101).

[98] An investigational immuno-therapy study of nivolumab compared to sorafenib as a first treatment in patients with advanced hepatocellular carcinoma. Available from: https://clinicaltrials.gov/ct2/show/NCT02576509, accessed May 2017.

[99] Segal NH, Hamid O, Hwu WJ, Massard C, Butler M, Antonia S, et al. A phase 1 multi-arm dose-expansion study of the anti-programmed cell deathligand-1 (PD-L1) antibody MEDI4736: preliminary data. European Society of Medical Oncology (ESMO) Meeting, Madrid, Spain, 26-30 September 2014. Abstract 5888 .

[100] A study of MEDI4736 with tremelimumab, MEDI4736 or tremelimumab monotherapy in unresectable hepatocellular carcinoma. Available from: https://clinicaltrials.gov/ct2/show/NCT02519348, accessed April 2017.

[101] Truong P, Rahal A, Kallail KJ. Metastatic hepatocellular carcinoma responsive to pembrolizumab. Cureus 2016;8:e631. doi: 10.7759/cureus.631.

[102] Pembrolizumab (MK-3475) in hepatocellular carcinoma. Available from: https://clinicaltrials.gov/ct2/show/NCT02940496, accessed January 2017.

[103] FDA Approval for Ipilimumab. Available from: https://www.cancer.gov/ about-cancer/treatment/drugs/fda-ipilimumab, accessed July 3, 2013.

[104] A study to evaluate the effectiveness, safety and tolerability of nivolumab and the combination nivolumab plus ipilimumab in patients with advanced liver cancer (CheckMate040). Available from: https://clinicaltrials.gov/ct2/ show/NCT01658878, accessed March 2017.

[105] Sangro B, Gomez-Martin C, de la Mata M, Iñarrairaegui M, Garralda E, Barrera $\mathrm{P}$, et al. A clinical trial of CTLA-4 blockade with tremelimumab in patients with hepatocellular carcinoma and chronic hepatitis C. J Hepatol 2013;59:81-88. doi: 10.1016/j.jhep.2013.02.022.
[106] Duffy AG, Ulahannan SV, Makorova-Rusher O, Rahma O, Wedemeyer H, Pratt $D$, et al. Tremelimumab in combination with ablation in patients with advanced hepatocellular carcinoma. J Hepatol 2017;66:545-551. doi: 10. 1016/j.jhep.2016.10.029.

[107] Nishikawa $H$, Enomoto $H$, Ishii $A$, Iwata $Y$, Miyamoto $Y$, Ishii $N$, et al. Prognostic significance of low skeletal muscle mass compared with proteinenergy malnutrition in liver cirrhosis. Hepatol Res 2016. doi: 10.1111/ hepr. 12843.

[108] Schütte K, Tippelt B, Schulz C, Röhl FW, Feneberg A, Seidensticker R, et al. Malnutrition is a prognostic factor in patients with hepatocellular carcinoma (HCC). Clin Nutr 2015;34:1122-1127. doi: 10.1016/j.clnu.2014.11.007.

[109] Yoshida T, Muto Y, Moriwaki H, Yamato M. Effect of long-term oral supplementation with branched-chain amino acid granules on the prognosis of liver cirrhosis. Gastroenterol Jpn 1989;24:692-698.

[110] Vilstrup H, Amodio P, Bajaj J, Cordoba J, Ferenci P, Mullen KD, et al. Hepatic encephalopathy in chronic liver disease: 2014 Practice Guideline by the American Association for the Study of Liver Diseases and the European Association for the Study of the Liver. Hepatology 2014;60:715-735. doi: 10.1002/hep. 27210.

[111] Marchesini G, Bianchi G, Merli M, Amodio P, Panella C, Loguercio C, et al. Nutritional supplementation with branched-chain amino acids in advanced cirrhosis: a double-blind, randomized trial. Gastroenterology 2003;124: 1792-1801. doi: 10.1016/S0016-5085(03)00323-8.

[112] Muto $Y$, Sato S, Watanabe A, Moriwaki H, Suzuki K, Kato A, et al. Effects of oral branched-chain amino acid granules on event-free survival in patients with liver cirrhosis. Clin Gastroenterol Hepatol 2005;3:705-713. doi: 10. 1016/S1542-3565(05)00017-0.

[113] Yoshiji H, Noguchi R, Namisaki T, Moriya K, Kitade $M$, Aihara $Y$, et al. Branched-chain amino acids suppress the cumulative recurrence of hepatocellular carcinoma under conditions of insulin-resistance. Oncol Rep 2013;30:545-552. doi: 10.3892/or.2013.2497.

[114] Ohno T, Tanaka Y, Sugauchi F, Orito E, Hasegawa I, Nukaya H, et al. Suppressive effect of oral administration of branched-chain amino acid granules on oxidative stress and inflammation in HCV-positive patients with liver cirrhosis. Hepatol Res 2008;38:683-688. doi: 10.1111/j.1872-034X. 2008.00319.x.

[115] Nishitani S, Horie M, Ishizaki S, Yano H. Branched chain amino acid suppresses hepatocellular cancer stem cells through the activation of mammalian target of rapamycin. PLoS One 2013;8:e82346. doi: 10.1371/journal. pone.0082346.

[116] Nishikawa H, Osaki Y, Inuzuka T, Takeda H, Nakajima J, Matsuda F, et al. Branched-chain amino acid treatment before transcatheter arterial chemoembolization for hepatocellular carcinoma. World J Gastroenterol 2012;18: 1379-1384. doi: 10.3748/wjg.v18.i12.1379.

[117] Ichikawa K, Okabayashi T, Maeda H, Namikawa T, Ilyama T, Sugimoto T, et al. Oral supplementation of branched-chain amino acids reduces early recurrence after hepatic resection in patients with hepatocellular carcinoma: a prospective study. Surg Today 2013;43:720-726. doi: 10 . 1007/s00595-012-0288-4

[118] Kuroda H, Ushio A, Miyamoto Y, Sawara K, Oikawa K, Kasai K, et al. Effects of branched-chain amino acid-enriched nutrient for patients with hepatocellular carcinoma following radiofrequency ablation: a one-year prospective trial. J Gastroenterol Hepatol 2010;25:1550-1555. doi: 10.1111/j. 1440-1746.2010.06306.x.

[119] Takeda $H$, Nishikawa $H$, Iguchi E, Ohara $Y$, Sakamoto A, Saito S, et al. Effect of treatment with branched-chain amino acids during sorafenib therapy for unresectable hepatocellular carcinoma. Hepatol Res 2014;44:302-312. doi: 10.1111/hepr.12125

[120] Chen L, Chen Y, Wang X, Li H, Zhang H, Gong J, et al. Efficacy and safety of oral branched-chain amino acid supplementation in patients undergoing interventions for hepatocellular carcinoma: a meta-analysis. Nutr J 2015; 14:67. doi: 10.1186/s12937-015-0056-6.

[121] Harding J], Abou-Alfa GK. Systemic therapy for hepatocellular carcinoma. Chin Clin Oncol 2013;2:37. doi: 10.3978/j.issn.2304-3865.2013.07.06. 